\title{
Y.S. Liao - L.C. Chen \\ Determination of mask opening size in creating a fluid hole on brittle material by double-side sand blasting
}

Received: 27 April 2004 / Accepted: 3 January 2005 / Published online: 31 August 2005

(C) Springer-Verlag London Limited 2005

\begin{abstract}
In creating a hole on brittle materials by double-side sand blasting, the rebounding sand particle flux during the process may result in underetching at the edge of the mask opening, and leads to a larger sized fluid hole than the desired one. Determination of the correct mask opening size was made mainly by trial and error in the past. In this paper, relationships between the mask opening size and desired size of a hole on both the front and the back sides of the substrate are derived. For the front side, by taking into account the underetching effect, an equation is derived based on the kinetic energy theory. For the back side, there is negligible rebounding sand particles, and the mask opening size is set to be equal to the desired size of the hole. Experiments were conducted to verify the derived relationships. It is found that the measured sizes of the eroded holes on both the front and the back sides of the wafer substrate are distributed normally. The desired hole sizes deviate slightly from the median of a normal distribution curve, and the maximum predicted errors are $2.4 \%$ and $3.0 \%$ for front side and the back side sand blasting, respectively. The very satisfactory result together with ANOVA and test of homogeneity of variance of the predicted errors for various hole size shows that the derived relationships is applicable for determination of the mask opening size in the sand blasting process.
\end{abstract}

Keywords Brittle material · Mask - Mask opening size ·

Sand blasting · Underetching

\section{Introduction}

Semiconductors, ceramics, glasses, and piezoelectric have special electronic, optical, physical, and mechanical properties, they

L.C. Chen $(\bullet)$. Y.S. Liao

Department of Mechanical Engineering,

National Taiwan University No. 1,

Sec. 4, Roosevelt Rd., Taipei, 106, Taiwan

E-mail: liichun@ntu.edu.tw

Tel.: +886-2-23626431

Fax: +886-2-23035181 are widely used in computers, consumer products, communications equipment, manufacturing industries, automobiles, and by the military. These materials possess the common characteristic of being hard, brittle, and difficult to process. In the process of such materials, it is always necessary to engage in a subsequent micromachining processing, such as drilling holes or ditching slots. Since the traditional machining processes are ineffective for such brittle materials, an extremely slow dry or wet etching process has been used in the past [1].

Research on sand blasting in the past was mainly focused on the negative effects of sand blasting to the machine element $[2,3]$. However recently, sand blasting has been proposed as a new, simple, and very fast mechanical etching method for the fabrication of micro systems on brittle materials $[4,5]$, the erosion rate is on the order of $1 \mathrm{~mm} / \mathrm{min}$ [6], much higher than that obtainable by dry or wet etching processes. The etching or erosion mechanism is based on material removal due to the generation of mico-cracks by sharp indenting particles [7, 8]. Whereas micro patterning resolution typically is around $50 \mu \mathrm{m}$ (for powder particle size of $30 \mu \mathrm{m}$ ) but can be smaller when smaller size erosion powders are used [6]. One example of application is to sand blast an etch ink slot on a single silicon substrate chip of an ink jet printhead as shown in Fig. 1.
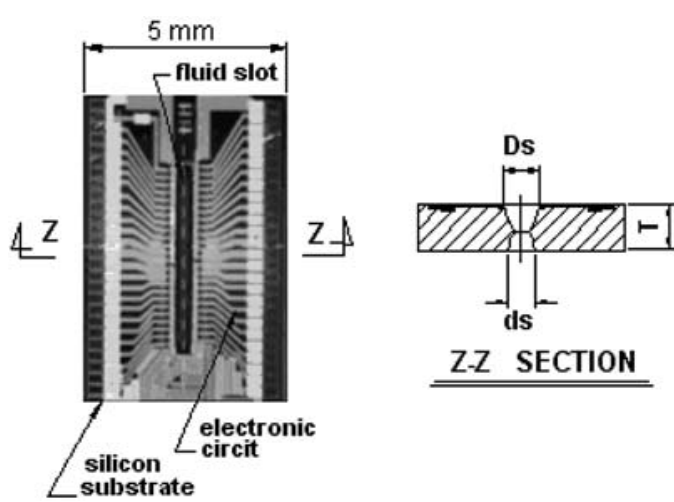

Z-Z SECTION

Fig. 1. A fluid slot on a single silicon substrate chip of an ink jet print head created by sand blasting 
When holes on a wafer substrate are to be created by such a technique, the mask must first be closely stuck on or magnetically attracted to the substrate, and after the front side sand blasting process, the inside contour of the eroded hole of the substrate approaches a cone shape, a small opening size appears at the bottom of the substrate and is always not fit for the desired size, the small opening will therefore need to be further expanded by back side sand blasting. Traditionally, a resin or metal was used as the mask material, this mask kept the sand from etching areas of the work piece that did not require processing. The mask can resist the blast etching from the front sandblast flux, but it is unable to resist the rebounding sand particle flux coming from the substrates before it is blasted through. Thus, underetching on the front side of the substrate occurs at the edge of the mask opening whereby the size of the created fluid hole actually blast-etched out is larger than the mask opening size. In the past, there was no suitable formula for calculating the correct mask opening size, any decision made had to be by trial and error or with the fine-tuning of the masking process [9]. The precision problem of the eroded holes caused by the mask underetching constrains the further applications of machining of brittle material by the sand blasting process. The present paper attempts to derive the relationships between the mask opening size and the desired size of a hole on both the front and the back sides of the substrate in the double side sand blasting process so that the mask opening size can be predicted beforehand and the accuracy of the size of the eroded hole can be improved. It is expected that when improvement has been achieved in accuracy of the size of the holes, the sand blasting process, with its higher rate of machining, will provide a potential alternation for the process of these brittle materials.

Relationships between the mask opening size and desired size of a hole on both the front and the back sides of the substrate in the double side sand blasting process are derived and given in Sect. 2. This is followed by experimental verification of the accuracy of the equation. The applicability of the derived relationships is also checked by statistical tests. Finally, numerous conclusions are drawn and given.

\section{Determination of mask opening size}

As shown in the right view of Fig. 1, it is desired to create a fluid slot of inlet size Ds and outlet size ds. A mask opening size in the front side blasting is first derived, then a mask opening size in the back side blasting.

\subsection{Derivation of mask opening size in front side erosion}

Assuming that the incoming particles are shot in with a velocity $V$ at an incidence angle $\theta$ from the horizontal direction. A vertical component of this velocity represented by $V_{y}$, is the principal source of downward erosion. After the initial impact of the incoming particle flux, a part of kinetic energy is lost and rebounding sand particles with relatively small velocity $V^{\prime}$ are reflected out toward the direction of $\theta^{\prime}$ with respect to the horizontal di- rection. The rebounding angle $\theta^{\prime}$ is determined experimentally, and it is about $\theta / 2$ [7]. A horizontal velocity component of this rebounding sand flux is represented by $V_{x}^{\prime}$ as shown in Fig. 2, and as described above, this component $V_{x}^{\prime}$ is, precisely, the principal energy that causes mask underetching.

It has been shown by Silkkerveer that the erosion rate is strongly dependent on the kinetic energy of the indenting particle and it is linearly proportional to the square of the velocity [10]. This relationship is represented by Belloy [11] as follows:

$$
\begin{aligned}
\frac{E_{\text {x rate }}}{E_{\text {y rate }}} & =\left(\frac{V^{\prime} \cos \theta}{V \sin \theta}\right)^{2}=\left(\frac{V^{\prime} \cos (\theta / 2)}{V \sin \theta}\right)^{2} \\
& =\left(\frac{V^{\prime}}{V}\right)^{2} \frac{1}{4 \sin ^{2}(\theta / 2)}
\end{aligned}
$$

in which $E_{y}$ rate represents the vertical erosion rate caused by the primary incoming particle flux, $E_{x \text { rate }}$ represents the horizontal lateral erosion rate. The erosion rate is defined as the ratio of the removed material weight to the overall weight of impacting particles. Again, the depth of erosion and erosion rate constitute a linear direct proportional relationship. Hence, if the depth of the vertical erosion and the depth of mask underetching are represented by $D_{y}$ and $D_{x}$, respectively, then

$$
\frac{D_{X}}{D_{Y}}=\frac{E_{\text {xrate }}}{E_{\text {y rate }}}=\left(\frac{V^{\prime}}{V}\right)^{2} \frac{1}{4 \sin ^{2}(\theta / 2)} .
$$

At the beginning of the sand blasting process, due to the influence of the mask thickness and the inclining of the blast sand flux, there occurs a so-called "flux shadow" effect whereby corners at the margin of the mask will temporarily not be subject to erosion and the erosion will start at the middle of the mask opening and extends toward all corners at the margin. As shown in Fig. 3, when rebounding sand particles begin to erode the material under the mask, the phenomenon of mask underetching occurs immediately. According to real experiments, when the depth of vertical erosion reached a depth of $0.8 D(D=$ mask opening size), that is, reaching the point $S$ in Fig. 3, the mask underetching starts to take place. In other words, because of the rebounding sand particles, the mask underetching occurs only at about the depth of wafer $D_{y}=T-0.8 D(T=$ thickness of wafer, $D=$ mask opening) as shown in Fig. 4, thus Eq. 3 can be

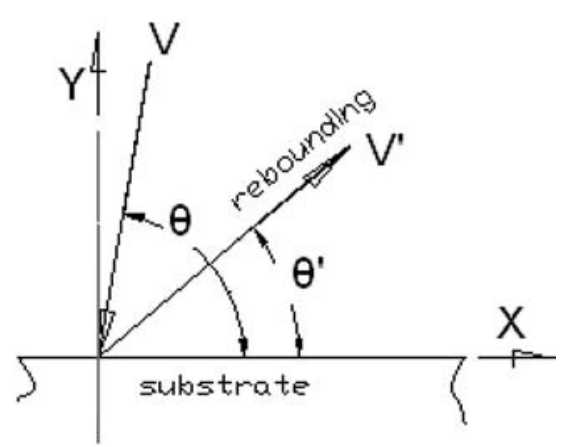

Fig. 2. Geometrical relationship of incoming and rebounding particles 


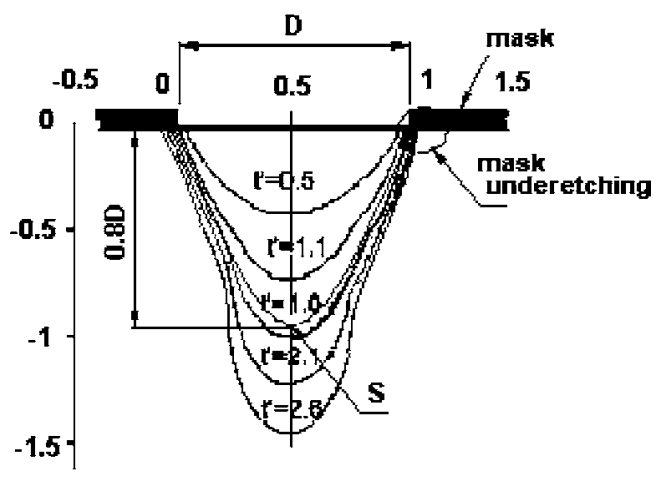

Fig. 3. The measured profiles of an eroded hole

written as:

$\frac{D_{x}}{D_{y}}=\frac{D_{x}}{T-0.8 D}=\left(\frac{V^{\prime}}{V}\right)^{2} \frac{1}{4 \sin ^{2}(\theta / 2)}$.

Denoting $\left(v^{\prime} / v\right)^{2}$ by $C$ and let the angle of incidence $\theta=90^{\circ}$, then Eq. 3 becomes:

$D_{x}=0.5 C(T-0.8 D)$.

Let mask opening size and thickness of wafer material be denoted by $D$ and $T$, respectively. Using Eq. 4 , it is possible to calculate the distance of the lateral mask underetching $D_{x}$, when vertical erosion reaches the bottom of the wafer. From this, the width $D s$ on the top of the wafer can be calculated when the wafer is first blast-etched throughout on the front side.

$D_{S}=D+2 D_{x}=D+2 \times 0.5 C(T-0.8 D)$

Rearranging the above equation and finding $C=0.25$ from experiment [7], then the mask opening size can be obtained as follows:

$D=\frac{D_{S}-0.25 T}{0.8}$.

When a hole on a chip with desired size $D s$ is needed, as shown in Fig. 4, Eq. 6 can be used to find the mask opening size $D$.

\subsection{Mask opening size in back side erosion}

After front side sand blasting, a small hole appeared at the bottom of the substrate, and the inside profile of the eroded hole approached a straight line and the small opening size $d a$ at the bottom of the substrate was $d a \approx D r-2 T \tan \beta$ as shown in Fig. 5. If the small opening size were not fit for the desired size, it would need to further expand by back side sand blasting. In back side erosion, because the bottom of the substrate has been eroded through, the rebounding sand flux is less, hence the equation derived in the previous section for the front side mask opening size is not applicable. Here, a large portion of the energy of incoming particles is absorbed by the pad beneath the eroded hole which was created in front side erosion and only a small part of re-

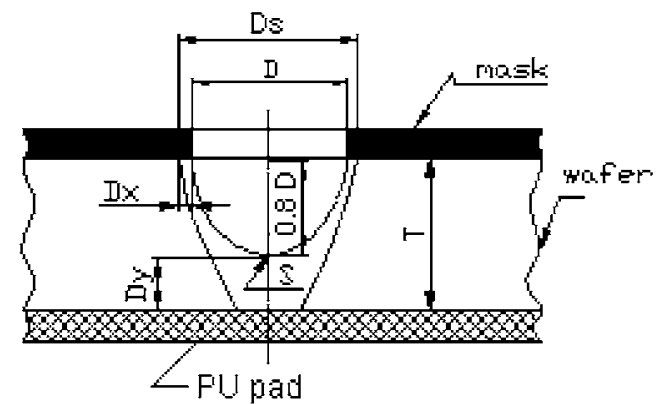

Fig. 4. Relationship between the desired size, thickness, and mask opening size

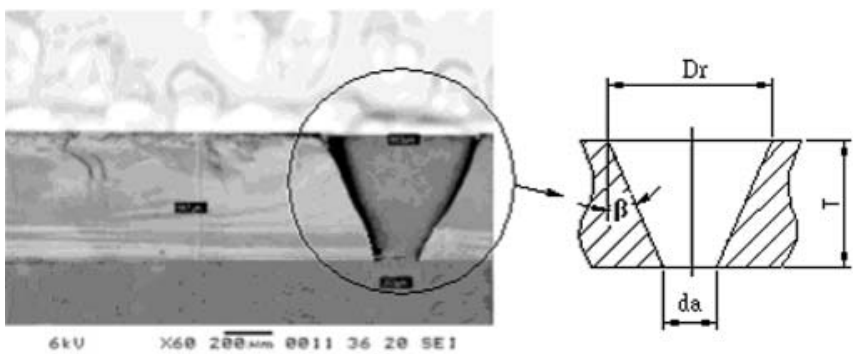

Fig. 5. The shape of an erosion-completed hole after front side sand blasting

bounding sand is again reflected out through a neck of the eroded hole but collides with incoming particles [12]. This results in a great decrease in the velocity of rebounding sand particles. As mentioned by Silkkerveer, the erosion rate is strongly dependent on the kinetic energy of the indenting particles and is linearly proportional to the square of the velocity [10]. Therefore, the influence on the mask underetching by the rebounding sand particles can be neglected and is independent of the desired size of opening ds and the thickness of the substrate $T$. Therefore, the mask opening size $\mathrm{d}$ in back side sand blasting can be designed to be the same as the desired size $d s$, i.e., $d=d s$.

\section{Experiment}

To verify the accuracy of the relationships derived in the previous section, some experiments were performed. It is desired to produce through holes of front side diameter $D s$ and back side diameter ds (referring to Fig. 6) on 5 in diameter silicon wafer. The thickness of the wafer and the desired hole sizes for each test were given in Table 1. For each test (ID No.) 500 holes were made.

Fig. 6. Illustration of desired hole size

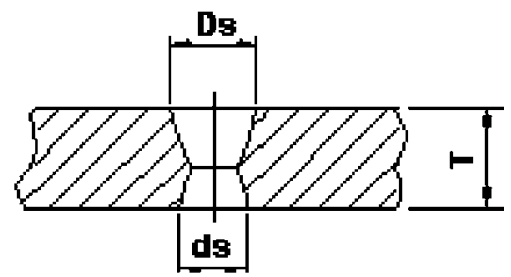


Table 1. The experimental size of eight sets of test pieces

\begin{tabular}{lrrrrrrrr}
\hline Thickness $(\mu \mathrm{m})$ & \multicolumn{3}{c}{600} & \multicolumn{5}{c}{525} \\
\hline ID IIO. & 1 & 2 & 3 & 4 & 5 & 6 & 7 & 8 \\
$D S(\mu \mathrm{m})$ & 575 & 475 & 375 & 275 & 540 & 440 & 340 & 240 \\
$d s(\mu \mathrm{m})$ & 400 & 330 & 230 & 130 & 400 & 300 & 200 & 100 \\
\hline
\end{tabular}

In the experiments, the mask opening size $D$ and $d$ in accordance with the derived equations were determined first. After the substrate had been stuck with a layer of photosensitive resin as a mask, more than 100 openings were made on the mask through the exposure and development process as shown in Fig. 7. Then the wafer was mounted on the fixture, overlaid with a layer of PU material to absorb energy when the hole was pierced and to prevent the wafer substrate from being broken by the sand flux. The nozzle performed uniform blast etching on the wafer substrate along the path as shown in Fig. 8. The front side of the substrate was first blast-etched throughout, it was then turned over to conduct blast etching on the back side. The small hole originally located on the bottom of the substrate was expanded until it reached the desired size of the hole. In the sand blasting process $28-40 \mu \mathrm{m}$ in diameter white $\mathrm{Al}_{2} \mathrm{O}_{3}$ sand particles were used. The sand blasting pressure is $p=2.5 \mathrm{~kg} / \mathrm{cm}^{2}$, and the distance from nozzle to substrate is $L=8 \mathrm{~cm}$.

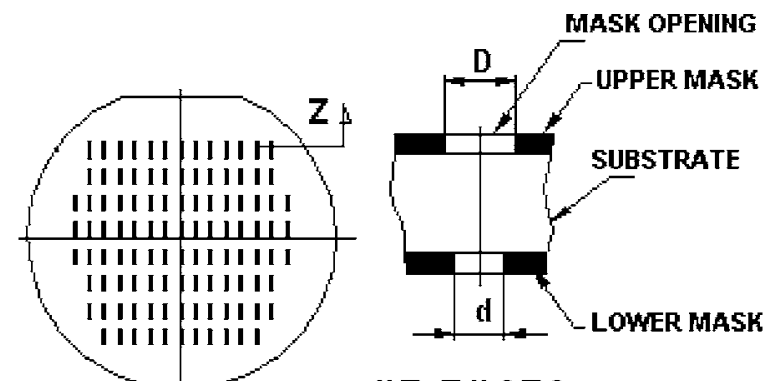

\section{"Z=Z" SEC}

Fig. 7. Wafer substrate with over 100 holes made thereon for testing

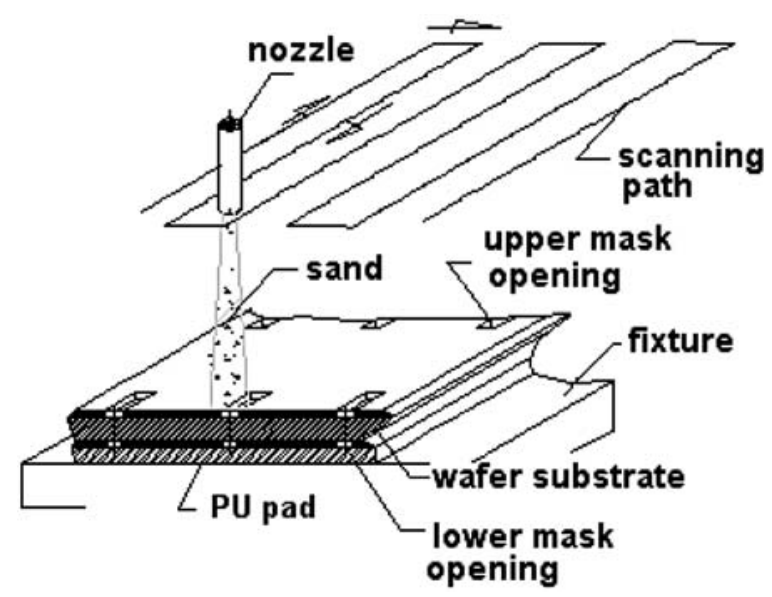

Fig. 8. Illustration of sand blasting path for testing

\section{Results and discussion}

\subsection{Results}

A SEM microphotograph of the shape of an erosion-completed hole is shown in Fig. 9. An optical microscope was used to measure the sizes of the front side, $D r$, and back side, $d r$, of the eroded hole. The measured $D r, d r$ and their corresponding numbers of occurrence for the four cases tested on the $600 \mu \mathrm{m}$ thickness wafer (ID. NO. 1-4) are drawn and given in Figs. 10 and 11, respectively. It can be seen that they are approximately normally distributed. Similar results are obtained for the $525 \mu \mathrm{m}$ thickness wafer as shown in Figs. 12

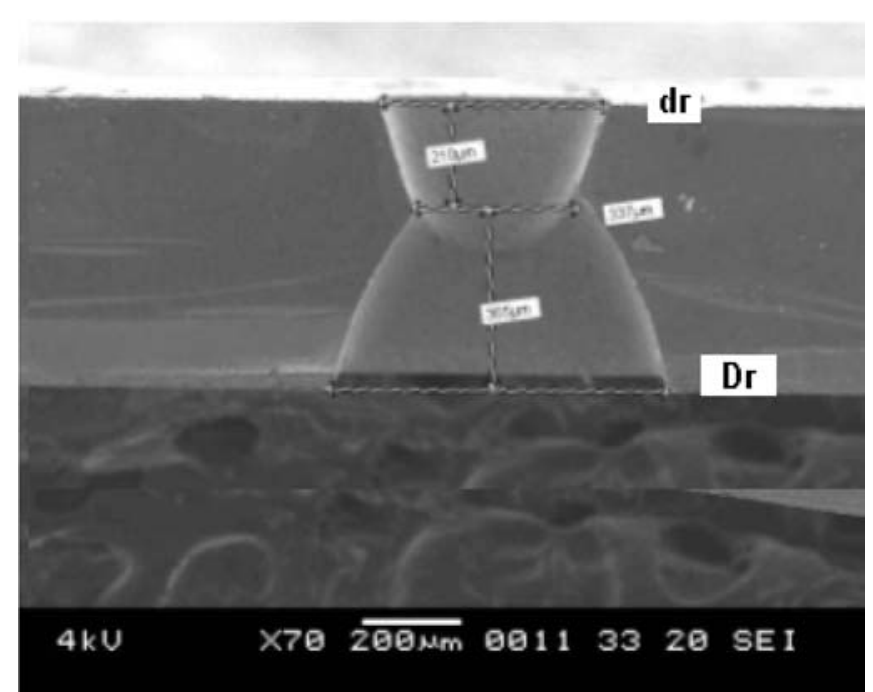

Fig. 9. The shape of an erosion- completed hole by double-side sand blasting

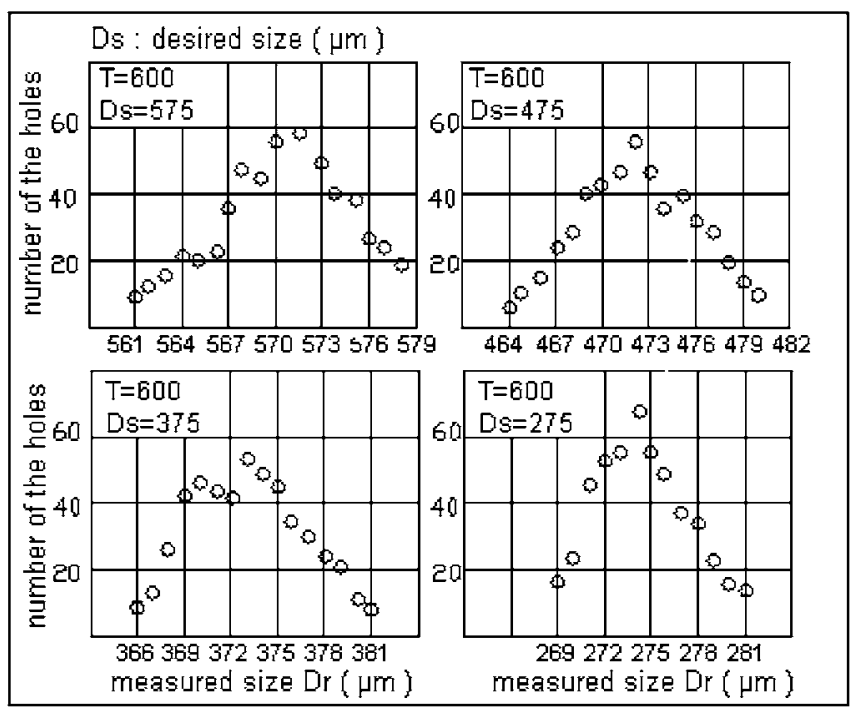

Fig. 10. Distribution of the measured size, $D r$, of the eroded holes for four different sizes of Ds on the $600 \mu \mathrm{m}$ thickness substrate 


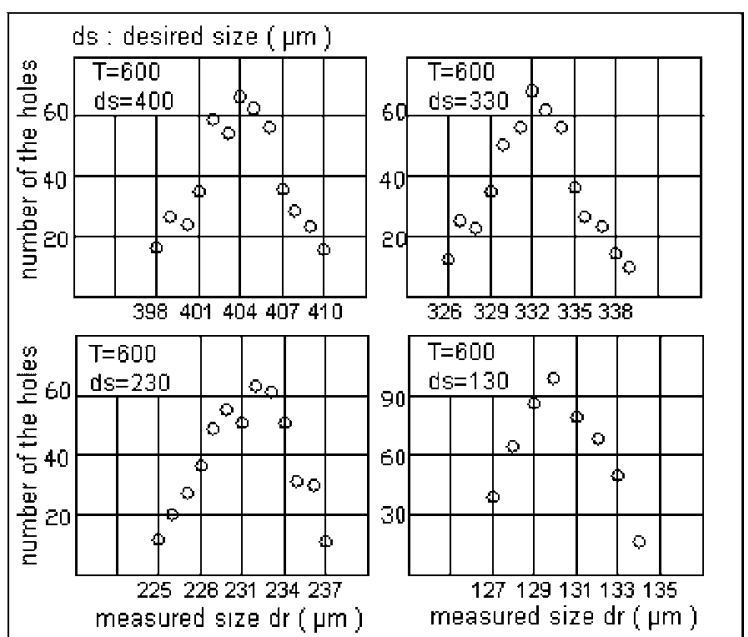

Fig. 11. Distribution of the measured size, dr, of the eroded holes for four different sizes of ds on the $600 \mu \mathrm{m}$ thickness substrate

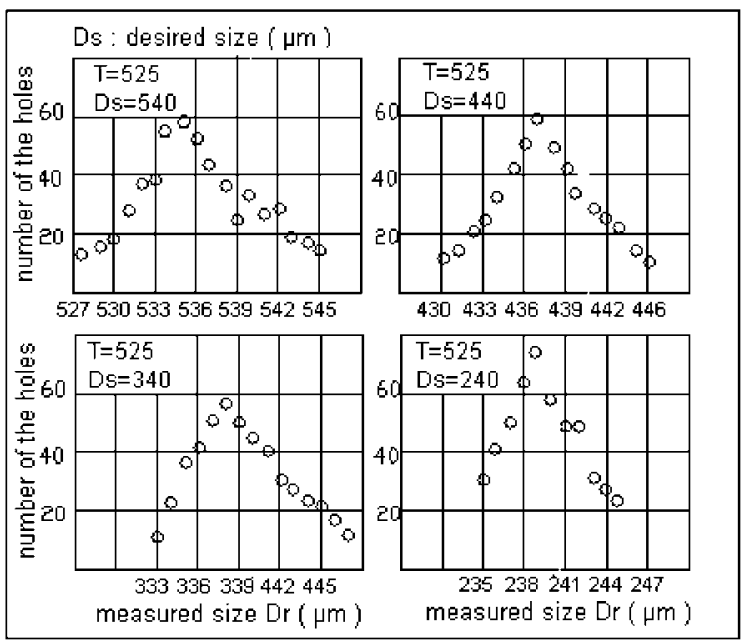

Fig. 12. Distribution of the measured size, Dr, of the eroded holes for four different sizes of Ds on the $525 \mu \mathrm{m}$ thickness substrate

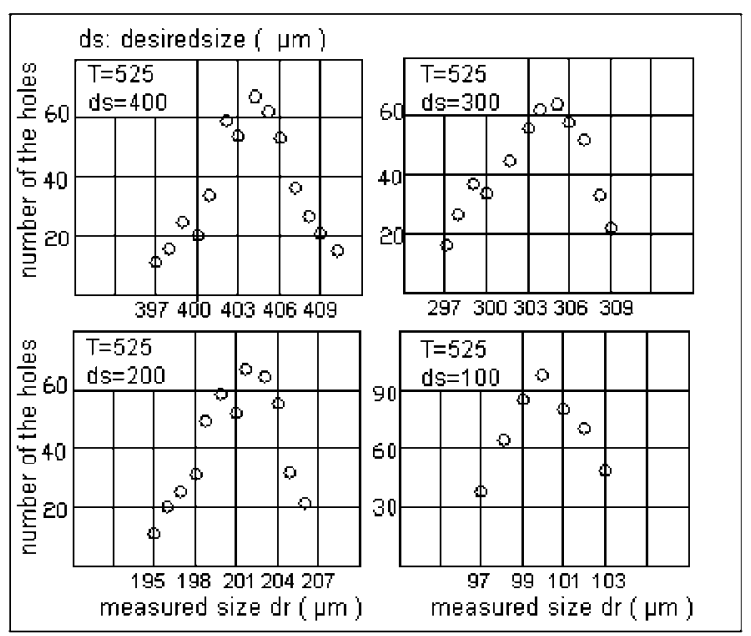

Fig. 13. Distribution of the measured size, dr, of the eroded holes for four different sizes of ds on the $525 \mu \mathrm{m}$ thickness substrate
Table 2a,b. Size of a front side erosion $\mathbf{b}$ back side erosion eroded holes on the $600 \mu \mathrm{m}$ thickness substrate

\begin{tabular}{lcccc}
\hline $\begin{array}{l}\text { a } \\
\text { Test } \\
\text { piece \# }\end{array}$ & $\begin{array}{c}\text { Desired size } \\
D S(\mu \mathrm{m})\end{array}$ & $\begin{array}{c}\text { Measured size } \\
(\text { min.-max. } \\
D R(\mu \mathrm{m})\end{array}$ & $\begin{array}{c}\text { Average size } \\
D a(\mu \mathrm{m})\end{array}$ & Error \% \\
\hline 1 & 575 & $561-578$ & 570 & 2.4 \\
2 & 475 & $464-480$ & 472 & 2.4 \\
3 & 375 & $366-381$ & 373 & 2.4 \\
4 & 275 & $269-281$ & 274 & 2.1 \\
\hline
\end{tabular}

\begin{tabular}{lcccc}
$\begin{array}{l}\text { b } \\
\text { Test } \\
\text { piece \# }\end{array}$ & $\begin{array}{c}\text { Desired size } \\
D S(\mu \mathrm{m})\end{array}$ & $\begin{array}{c}\text { Measured size } \\
(\text { min.-max. } \\
D R(\mu \mathrm{m})\end{array}$ & $\begin{array}{c}\text { Average size } \\
D a(\mu \mathrm{m})\end{array}$ & Error \% \\
\hline 1 & 400 & $397-410$ & 403 & 2.5 \\
2 & 330 & $326-339$ & 332 & 2.7 \\
3 & 230 & $225-237$ & 231 & 3.0 \\
4 & 130 & $127-134$ & 100 & 3.0 \\
\hline
\end{tabular}

Table 3a,b. Size of a front side erosion $\mathbf{b}$ back side erosion eroded holes on the $525 \mu \mathrm{m}$ thickness substrate

\begin{tabular}{|c|c|c|c|c|}
\hline $\begin{array}{l}\text { a } \\
\text { Test } \\
\text { piece \# }\end{array}$ & $\begin{array}{l}\text { Desired size } \\
D S(\mu \mathrm{m})\end{array}$ & $\begin{array}{c}\text { Measured size } \\
\text { (min.-max.) } \\
D R(\mu \mathrm{m})\end{array}$ & $\begin{array}{c}\text { Average size } \\
D a(\mu \mathrm{m})\end{array}$ & Error \% \\
\hline $\begin{array}{l}1 \\
2 \\
3 \\
4\end{array}$ & $\begin{array}{l}540 \\
440 \\
340 \\
240\end{array}$ & $\begin{array}{l}528-545 \\
430-446 \\
333-347 \\
235-245\end{array}$ & $\begin{array}{l}536 \\
438 \\
339 \\
239\end{array}$ & $\begin{array}{l}2.2 \\
2.2 \\
2.2 \\
2.0\end{array}$ \\
\hline $\begin{array}{l}\mathbf{b} \\
\text { Test } \\
\text { piece \# }\end{array}$ & $\begin{array}{l}\text { Desired size } \\
D S(\mu \mathrm{m})\end{array}$ & $\begin{array}{c}\text { Measured size } \\
(\min .-\max .) \\
D R(\mu \mathrm{m})\end{array}$ & $\begin{array}{c}\text { Average size } \\
D a(\mu \mathrm{m})\end{array}$ & Error \% \\
\hline $\begin{array}{l}1 \\
2 \\
3 \\
4\end{array}$ & $\begin{array}{l}400 \\
300 \\
200 \\
100\end{array}$ & $\begin{array}{r}397-410 \\
296-308 \\
195-206 \\
97-103\end{array}$ & $\begin{array}{l}403 \\
302 \\
201 \\
100\end{array}$ & $\begin{array}{l}2.5 \\
2.7 \\
3.0 \\
3.0\end{array}$ \\
\hline
\end{tabular}

and 13. Tables 2 and 3 show the measured maximum size, minimum size, the average size, and the maximum error with respect to the desired hole size in percentage for the $600 \mu \mathrm{m}$ and $525 \mu \mathrm{m}$ thickness wafer, respectively. The maximum errors are $2.4 \%$ and $3.0 \%$, respectively for the front side and back side sand blasting, and fairly accurate size of the holes are achieved.

\subsection{Statistical tests}

To further check if the derived relationships lead to consistent results (i.e., same mean error and variance) irrespective to the wafer thickness and desired hole size, ANOVA [13] and test of homogeneity of variance of the predicted error (i.e., the difference between measured size and desired size) for the front side hole and back side hole were conducted, respectively. 
Table 4a,b. The results of a ANOVA and $\mathbf{b}$ Test of homogeneity of variance for front side hole

\begin{tabular}{|c|c|c|c|c|}
\hline $\begin{array}{l}\text { Source of } \\
\text { variation }\end{array}$ & $\begin{array}{l}\text { Sum of } \\
\text { square }\end{array}$ & $\begin{array}{l}\text { Degree of } \\
\text { freedom }\end{array}$ & $\begin{array}{l}\text { Mean } \\
\text { square }\end{array}$ & F-value \\
\hline $\begin{array}{l}\text { Between } \\
\text { Within } \\
\text { Total }\end{array}$ & $\begin{array}{r}61.187 \\
69697.528 \\
69758.715\end{array}$ & $\begin{array}{r}7 \\
3992 \\
3999\end{array}$ & $\begin{array}{r}8.741 \\
17.309\end{array}$ & 0.505 \\
\hline $\begin{array}{l}\text { b } \\
\text { Levence } \\
\text { statistics }\end{array}$ & $\begin{array}{c}\text { Numerator's } \\
\text { degree of freedom }\end{array}$ & \multicolumn{2}{|c|}{$\begin{array}{l}\text { Denominator's } \\
\text { degree of freedom }\end{array}$} & $\mathrm{p}$-Value \\
\hline 0.509 & 7 & \multicolumn{2}{|c|}{3992} & 0.676 \\
\hline
\end{tabular}

Table 5a,b. The results of a ANOVA and $\mathbf{b}$ Test of homogeneity of variance for back side hole

\begin{tabular}{|c|c|c|c|c|}
\hline $\begin{array}{l}\text { a } \\
\text { Source of } \\
\text { variation }\end{array}$ & $\begin{array}{l}\text { Sum of } \\
\text { square }\end{array}$ & $\begin{array}{l}\text { Degree of } \\
\text { freedom }\end{array}$ & $\begin{array}{l}\text { Mean } \\
\text { square }\end{array}$ & F-value \\
\hline $\begin{array}{l}\text { Between } \\
\text { Within } \\
\text { Total }\end{array}$ & $\begin{array}{r}73.570 \\
33920.024 \\
33993.594\end{array}$ & $\begin{array}{r}7 \\
3992 \\
3999\end{array}$ & $\begin{array}{r}10.510 \\
8.497\end{array}$ & 1.237 \\
\hline $\begin{array}{l}\text { b } \\
\text { Levence } \\
\text { statistics }\end{array}$ & $\begin{array}{c}\text { Numerator's } \\
\text { degree of freedom }\end{array}$ & \multicolumn{2}{|c|}{$\begin{array}{c}\text { Denominator's } \\
\text { degree of freedom }\end{array}$} & p-Value \\
\hline 0.543 & 7 & \multicolumn{2}{|c|}{3992} & 0.581 \\
\hline
\end{tabular}

The results of ANOVA and test of homogeneity of variance of the predicted errors for the front side hole are given in Table $4 \mathrm{a}$ and $\mathrm{b}$, and those for the back side hole are displayed in Table 5a and b. For both conditions, from ANOVA the computed $F$ value is less than $F_{0.05}(7, \infty)=2.01$, hence statistically there is no difference of the mean of the predicted errors for all tested cases. The p-value from the test of homogeneity of variance is larger than 0.05 . This indicates that the dispersion of the error with respect to mean error is the same. Based on these two tests, it is concluded that the distributions of the measured size for all tested cases are the same irrespective to the wafer thickness and size of the holes.

\subsection{Discussion}

The fairly small predicted error together with very consistent distribution of the predicted error irrespective to the wafer thickness and the size of the desired hole demonstrate that the derived relations are applicable for determination of the correct mask opening size in double side sand blasting process. However, its use may be limited and affected by the following conditions.

1. The equations derived in this paper are based on the assumption that the thickness of the mask is sufficient enough to keep the substrate from the erosion of sand blasting.
2. In front side sand blasting, the phenomenon of mask underetching occurs when the depth of vertical erosion reaches a depth of the substrate, and from the actual experiments, the depth was estimated as $0.8 D(D=$ mask opening size $)$. Therefore, the problem of mask underetching may not be taken into consideration in the decision of mask opening size when the thickness of work substrate $T$ is less than $0.8 D$, or in other words, Eq. 6 is valid only when $T>0.8 D$.

3. As mentioned above, the starting point of mask underetching was estimated to be $0.8 D$ from the top of the substrate, which is a measurement value, and, as such, may contain a small measurement error which results therefore in inducing some error to Eq. 6.

4. In back side erosion, because the bottom of the substrate has been eroded through, a large portion of the energy of incoming particles is absorbed by the pad beneath the opening, which results in disability of rebounding sand flux. Therefore, mask underetching caused by rebounding sand flux may be related to the material of the pad. In the present work, all experimental data were obtained using a pad of PU material.

5. Because static electricity will arise around where high speed sand flows and influence the path of sand flow, hence to ensure the precision of products it is necessary to eliminate its occurrence effectively when sand blasting is in progress.

\section{Conclusion}

In this paper, relationships are derived whereby the mask opening size can be rapidly calculated from the desired size of the hole rather than by the trial-and-error method used frequently in the past. Experimental verification has shown that the derived relationships lead to very accurate result; the maximum predicted errors are $2.4 \%$ and $3.0 \%$ for front side and back side sand blasting, respectively. The statistical tests of the predicted errors also demonstrate that the relationships result in very consistent distribution of the eroded holes irrespective to the size of the desired hole and wafer thickness. It is concluded that the derived relationships are applicable for determination of mask opening size in advance, and will contribute to the sand blasting process.

Acknowledgement The authors would like to thank Mr. Jack Hsu, the engineer of Kernel Dynamics Inc., Taiwan for making the experiments and measurements on this study.

\section{References}

1. Sin MW, Song JG (2002) Study on the photoelectrochemical etching process of semiconducting $6 \mathrm{H}-\mathrm{SiC}$ wafer. Mater Sci Engineering B B95:191-194

2. Abstract book of the International Conference on Erosive and Abrasive Wear. Cambridge, 13-17 Sept. 1998, University of Cambridge 
3. Hutchings IM, Macmillan NH, Rickerby DG (1981) Further studies of the oblique impact of a hard sphere against a ductile solid. Int J Mech Sci 23:639-646

4. Wensink H, Berenschot JW, Jansen HV, Elwenspoek MC (2000) High resolution powder blast micromachining. In: Proceedings of the 13th IEEE MEMS Conference, Japan, IEEE, Piscataway, NJ, USA, pp 769-774

5. Belloy E, Sayah A, Gijs MAM (2002) Micromachining of glass inertial sensor. J Micro-electromech Syst 11(1):85-90

6. Belloy E, Thurre S, Walckers E, Sayah A, Gijs MAM (2000) The introduction of powder blasting for sensor and microsystem applications. Sens Actuators A 84:330-337

7. Slikkerveer PJ (1999) Mechanical etching of glass by powder blasting. Dissertation, Eindhoven University of Technology
8. Buijs M (1994) Erosion of glass as modeled by indentation theory, $\mathbf{J}$ Am Ceram Soc 77:1676-1678

9. Park D-S, Cho M-W, Lee H, Cho W-S (2004) Micro-grooving of glass using micro-abrasive jet machining. J Mater Process Technol 146:234-240

10. Slikkerveer PJ, Bouten PCP, in't Veld FH, Scholten H (1998) Erosion and damage by sharp particles. Wear 217:237-250

11. Belloy E, Sayah A, Gijs MAM (2001) Oblique powder blasting for three-dimensional micromachining of brittle materials. Sens Actuators A 92:358-363

12. in't Veld FH, Slikkerveer PJ (1998) Toward prediction of flux effects in powder blasting nozzles. Wear 215:131-136

13. Snedecor GW, Cochran WG (1980) Statistical Methods. Iowa State University Press, pp 215-219 